\title{
Commentaries on \\ 'Vitamin C for preventing and treating the common cold' with responses from the review author
}

\author{
Evidence-Based Child Health
}

http://dx.doi.org/10.1002/ebch.261

See the commentaries at:

www.mv.helsinki.fi/home/hemila/H/2008 L EBCH.pdf

\section{Reply to Shamseer and Vohra's Commentary}

\author{
by \\ Harri Hemilä, MD, PhD \\ Department of Public Health, \\ University of Helsinki, Finland \\ harri.hemila@helsinki.fi \\ http://www.mv.helsinki.fi/home/hemila/
}

I share Shamseer and Vohra's concern about publication bias in the leading medical journals. For example, in 1975 the American Journal of Medicine published a highly influential review on vitamin $\mathrm{C}$ and the common cold by Thomas Chalmers (1). When I became interested in the same topic, I was puzzled by the great discrepancy between the original trial reports and Chalmers' selection and description of them. I wrote a critique of Chalmers' review, but my paper was rejected by the same journal and it was published in a minor journal $(2,3)$. Obviously, the leading journals must be highly selective in the acceptance of papers, but that leads to bias in reports reaching wide readerships.

Nevertheless, I do not agree that publication bias might substantially affect the main conclusions of our Cochrane review (4). We are drawing several conclusions and they should be considered individually. We concluded that there is strong evidence of heterogeneity in the effect of vitamin $\mathrm{C}$ on common cold incidence. Vitamin $\mathrm{C}$ halved the number of colds in participants under heavy acute physical stress, but had no effect on the incidence of colds in the general community. How could such heterogeneity be generated by publication bias? Furthermore, based on 30 trials with 9676 recorded common cold episodes in all, we concluded that regular vitamin C supplementation shortens the duration of colds. Proposal that this effect is explained by publication bias presumes that several large trials with negative findings remain unpublished which does not seem a reasonable assumption. Publication bias may affect the point estimates of our analyses, but it is unlikely to affect our main conclusions.

Shamseer and Vohra comment that we might have included more data bases in our literature searches. However, even though MEDLINE and EMBASE can miss some trials published in CAM journals, we also searched the Cochrane CENTRAL which collects trials independent of them being recorded in MEDLINE or EMBASE. Furthermore, we describe in the Cochrane review that I have been actively collecting literature on vitamin $\mathrm{C}$ and common cold trials for over two decades. Because of my familiarity with the literature, I pointed out that an extensive literature search $(5,6)$ had missed six placebo-controlled trials (7). If Shamseer and Vohra consider that we may have missed relevant trials, they should search and describe examples instead of just speculating. Furthermore, as described above, our main conclusions are not sensitive to a few unidentified or 
unpublished trials.

Shamseer and Vohra state that we did not mention whether foreign language trials were sought and included. We did not describe selection by language which means that we selected trials independent of their language. The reference section of our review shows that we found and assessed trials published in Finnish, German, Spanish and Swedish.

Shamseer and Vohra argue that we should have constructed a funnel plot to explore the possibility of publication bias. Funnel plot has been popular; however, it is not a valid method. For example, different metrics lead to different shapes of the funnel plot. Furthermore, asymmetry can arise from biological heterogeneity so that asymmetry is no evidence of publication bias. Because of various problems, the use of the funnel plot has been strongly discouraged (8). In fact, our Cochrane review serves as a good example against the funnel plot. The six trials with participants under heavy acute physical stress, which found that vitamin $\mathrm{C}$ halved the number of colds, are all small. In a funnel plot of all 30 trials measuring incidence, these six small trials would lead to asymmetry. Thus, the funnel plot would "explain" the positive findings by publication bias, which would discourage further trials. In contrast, our subgroup analysis in which the positive results are explained by the special participants and conditions suggests direction for further research to test a justified hypothesis.

Shamseer and Vohra notice that we presented subgroup analysis for children for only one of five primary outcomes. In the incidence analysis, statistically significant heterogeneity disappeared when we divided trials to those with participants under acute physical stress and to those with participants of the general community. Trials with children are consistent with the pooled estimates of these two subgroups. The largest trial with children of the general community, by Ludvigsson et al. with 615 Swedish schoolchildren (9), found no effect by vitamin C on common cold incidence consistent with the adult trials in the general community. The single trial with children under acute physical stress, by Ritzel at a skiing school in the Swiss Alps (10), found 45\% (95\% CI: 5 to 68\%) reduction in common cold incidence consistent with five trials with adults. Another outcome was the severity of colds in regular supplementation trials. We divided trials to two subgroups by the outcome: severity measured by a severity score and by the mean days off work or school $(\mathrm{P}=0.004$ for the benefit of vitamin $\mathrm{C}$ over placebo in the two subgroups with 15 trials). The complex outcome and the limited number of trials did not allow further subgroup analyses. Two outcomes were restricted to therapeutic trials and we state that "none of the therapeutic trials examined the effect of vitamin C on children”. Thus, there are clear reasons why we presented subgroup analysis for children for only one of the five outcomes.

I agree with Shamseer and Vohra's comment that generalizing our results is hampered by the fact that most of the trials were carried out in developed countries. On the other hand, a group of four trials in the UK with schoolboys and male students found a 30\% (95\% CI: 19 to 40\%) reduction in common cold incidence by vitamin C supplementation (11). This subgroup is mentioned in our discussion, but two of the trials used doses less than $200 \mathrm{mg}$ /day and were therefore excluded from the Cochrane analyses. Nevertheless, as regards the developing countries, this group of trials is interesting, because at the time of those four trials the dietary vitamin $C$ intake in the UK was substantially lower than in other western countries and might have been suboptimal (11). A Canadian trial with adults also suggested that vitamin $\mathrm{C}$ supplementation effect might be modified by dietary vitamin C intake (12). "Days confined to house per subject" was reduced by $48 \%$ in participants who had low intake of fruit juices and by 22\% in those who had high intake of juices; vitamin C dosage was $1 \mathrm{~g}$ /day regularly and $3 \mathrm{~g}$ /day extra during colds (12). Thus, as Shamseer and Vohra suggest, it seems possible that vitamin $\mathrm{C}$ might have a greater effect on the common cold and other respiratory infections (13) in developing countries in which low dietary vitamin C intake and high burden of respiratory infections coexist. 


\section{REFERENCES}

1. Chalmers TC. Effects of ascorbic acid on the common cold: an evaluation of the evidence. Am J Med 1975;58:532-536. http://dx.doi.org/10.1016/0002-9343\%2875\%2990127-8

2. Hemilä H, Herman ZS. Vitamin C and the common cold: a retrospective analysis of Chalmers' review. J Am Coll Nutr 1995;14:116-123. http://www.mv.helsinki.fi/home/hemila/H/HH 1995.pdf http://dx.doi.org/10.1080/07315724.1995.10718483

3. Hemilä H. Do vitamins C and E affect respiratory infections? [PhD Thesis]. Helsinki, Finland: University of Helsinki, 2006:36-38. http://hdl.handle.net/10138/20335

4. Douglas RM, Hemilä H, Chalker E, Treacy B. Vitamin C for preventing and treating the common cold. Cochrane Database Syst Rev 2007;3(Art. No.: CD000980).

5. Kleijnen J, Riet G, Knipschild PG. Vitamin C and the common cold; a review of the megadose literature [in Dutch]. Ned Tijdschr Geneeskd 1989;133;1532-1535. http://www.ntvg.nl/publicatie/vitamine-c-en-verkoudheid-overzicht-van-274166/volledig http://www.mv.helsinki.fi/home/hemila/reviews/Kleijnen 1989.pdf

6. Kleijnen J, Knipschild P. The comprehensiveness of Medline and Embase computer searches. Pharm Weekbl Sci Ed 1992;14:316-320. http://dx.doi.org/10.1007/BF01977620

7. Hemilä H. Do vitamins C and E affect respiratory infections? [PhD Thesis]. Helsinki, Finland: University of Helsinki, 2006:20,38-40.

http://hdl.handle.net/10138/20335

8. Lau J, Ioannidis JPA, Terrin N, Schmid CH, Olkin I. The case of the misleading funnel plot. BMJ 2006;333:597-600.

9. Ludvigsson J, Hansson LO, Tibbling G. Vitamin C as a preventive medicine against common colds in children. Scand J Infect Dis 1977;9:91-98.

http://www.ncbi.nlm.nih.gov/pubmed/897573 http://www.mv.helsinki.fi/home/hemila/CC/Ludvigsson 1977 ch.pdf

10. Ritzel G. Critical analysis of the role of vitamin $C$ in the prophylaxis and treatment of the common cold [in German]. Helv Med Acta 1961;28:63-68.

http://www.mv.helsinki.fi/home/hemila/T3.pdf

11. Hemilä H. Vitamin C intake and susceptibility to the common cold. Br J Nutr 1997;77:59-72. Discussion in: 1997;78:857-866. http://dx.doi.org/10.1017/S0007114500002889 http://dx.doi.org/10.1079/BJN19970201

12. Anderson TW, Reid DBW, Beaton GH. Vitamin C and the common cold: a double-blind trial. Can Med Assoc J 1972;107:503-508. Correction in: 1973;108:133. http://www.ncbi.nlm.nih.gov/pmc/articles/PMC1940935/ http://www.ncbi.nlm.nih.gov/pmc/articles/PMC1941144/

13. Hemilä H, Louhiala P. Vitamin C may affect lung infections. J R Soc Med 2007;100:495-498. https://doi.org/10.1177/014107680710001109 